\title{
Visual search performance in maps by Brazilian population
}

\author{
Ítalo Sousa de Sena ${ }^{\mathrm{a}, *}$, Zdeněk Stachoň $^{\mathrm{a}}$, Čeněk Šašinka ${ }^{\mathrm{b}}$, Petr Kubíček $^{\mathrm{a}}$ \\ ${ }^{a}$ Department of Geography, Faculty of Science, Masaryk University, desena@mail.muni.cz, zstachon@geogr.muni.cz, \\ kubicek@geogr.muni.cz. \\ ${ }^{b}$ Division of Information and Library Studies and HUME Lab, Faculty of Arts, Masaryk University, ceneksasinka@ gmail.com \\ * Corresponding author
}

Keywords: Visual search, Selective attention, Cartographic stimuli

\begin{abstract}
:
Theoretical cartography studies have been taking advantage of online tools to perform experiments in ways that allow for tracking user's behavior and collecting data. The main way to investigate how people interact with cartographic stimuli is by performing map reading tasks. These types of tasks can vary in level of complexity. One of the basic processes to measure people's performance is by visual search in maps, when the user needs to identify a specific target represented on a map [1].

In this research we aim to investigate the performance of Brazilian users based on their response time (efficiency) and correctness (effectiveness) in visual search tasks in maps. To achieve that we designed a test where the participants need to localize specific map symbols. We compared the efficiency and effectiveness for two different types of symbols: iconic and schematic [2].

The test consisted of a slide with one symbol on the left and complex visual stimuli on the right. The visual stimuli are a set of symbols distributed on top of a basic map background. For each slide the participant needed to identify the specific symbol displayed on the map. A total of 60 slides were shown. We divided the participants in two equal groups depending on the type of symbols.

The participants were Brazilian with backgrounds in different fields that require some degree of map reading proficiency (geography, architecture, civil engineering, environmental engineering, forest engineering). Since the tests are still ongoing, we are not able to specify the sample size at the moment. The data was collected fully online using the Hypothesis platform [3]. In order to control the experiment setting, we ensured the participants have had access to a computer screen with at least 21,5 inches size.

The suitable participants received an email message with instructions to perform the test and a video with detailed information on how to access the platform and how to ensure a proper setting to perform the test.

The data was collected in two rounds during one month each. The first round was in May 2021 and the second in June 2021.

We hypothesized to see a minor response time for iconic symbols in comparison to schematic.

There were limitations and particularities during the data collection in the context, the period when it was performed and origin and participant background. The context limitation caused by the COVID-19 pandemic forced us to perform the whole data collection online, without any physical contact with the participants. This setting may have caused challenges in guaranteeing the ecological validity of the data. Although, another call for participants is possible, altering the environment conditions. If the participant has a webcam and the test administrator is simultaneously online with the user, it may guarantee a better control of the experiment setting.

The second issue regards computer screens with the proper screen size. Many Brazilians have only access to laptops with screen sizes smaller than 17 inches or smartphones. This substantially reduced the availability of suitable participants to attend the test.

One particular aspect of performing surveys with the participants from Brazil concerns compensating them with cash. It surprised them since it is not ordinary in this country compensating people for this type of research.

Despite those issues, the possibility of performing the test online demonstrated a potentiality of using the platform to collect data remotely in any location with a proper internet connection. The recorded video detailing how to set up the test was a useful way to guarantee the availability of information to all participants.
\end{abstract}




\section{Acknowledgements:}

The contribution was supported by the Czech Science Foundation grant "The Influence of Socio-Cultural Factors and Writing Systems on the Perception and Cognition of Complex Visual Stimuli" (GC19-09265J). This work was also supported from Operational Programme Research, Development and Education - Project „Postdoc2MUNI“ (No. CZ.02.2.69/0.0/0.0/18_053/0016952).

\section{References:}

[1] Stachoň Z, Šašinka Č, Konečný M, Popelka S and Lacko D (2020) 'An Eye-Tracking Analysis Of Visual Search Task On Cartographic Stimuli', in Bandrova T, Konečný M and Marinova S (eds) 8th International Conference on Cartography \& GIS: Proceedings, Bulgarian Cartographic Association, 1:36-41.

[2] Stachoň Z, Šašinka Č, Čeněk J, Štěrba Z, Angsuesser S, Fabrikant SI, Štampach R and Morong K (2019) 'Crosscultural differences in figure-ground perception of cartographic stimuli', Cartography and Geographic Information Science, 46(1):82-94, doi:10.1080/15230406.2018.1470575.

[3] Šašinka Č, Morong K and Stachoň Z (2017) 'The Hypothesis Platform: An Online Tool for Experimental Research into Work with Maps and Behavior in Electronic Environments', ISPRS International Journal of Geo-Information, 6(12):407-428, doi:10.3390/ijgi6120407. 